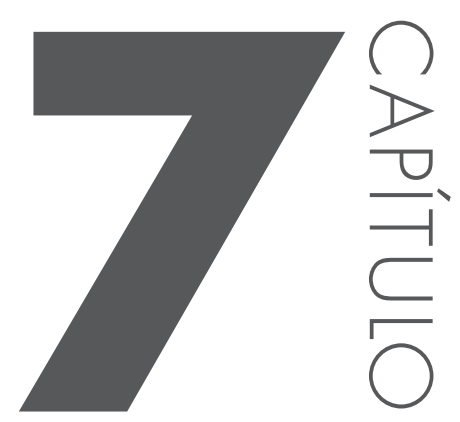

\title{
SUSTENTABILIDADE AMBIENTAL NA MENSURAC̣ÃO DA FELICIDADE
}

Elizabeth Borelli (PUCSP)

Ana Rafaela Torres (PUCSP)

\section{RESUMO}

Há um desafio no século XXI em relação a indicadores de mensuração da qualidade de vida dos países, não apenas baseados em indicadores como expectativa de vida, educação e produto interno bruto, mas que considerem, também, o grau de satisfação da população em relação a bens públicos subjetivos. Este artigo se propõe a analisar a nova métrica de desenvolvimento, que se fundamenta na consecução do bem-estar social com sustentabilidade ambiental, através do indicador da Felicidade Interna Bruta (FIB). Partindo desse pressuposto, o objetivo da análise se concentra em avaliar até que ponto o FIB se constitui numa medida que complementa o Produto Interno Bruto (PIB), de forma a orientar os tomadores de decisão de políticas públicas no sentido de 
uma melhoria na qualidade de vida. Para tanto, foram revisadas as colocações conceituais de alguns autores sobre felicidade e sustentabilidade, bem como, utilizados métodos estatísticos de análise, como correlação entre variáveis e análise de regressão, considerando-se as nove dimensões que compõem o FIB, quais sejam: padrão de vida econômico, governança, educação, saúde, vitalidade comunitária, resiliência ambiental, acesso à cultura, gerenciamento equilibrado do tempo e bem estar psicológico. Concluiu-se que o Produto Interno Bruto (PIB) é um indicador incompleto, e que o FIB seria uma alternativa complementar, indicando um melhor caminho para a felicidade.

PALAVRAS CHAVE: Felicidade Interna Bruta, Produto Interno Bruto, Sustentabilidade 


\section{INTRODUC̣ÃO}

O conceito de felicidade vem sendo abordado desde a Antiguidade clássica. Aristóteles (384 a.C. a 322 a.C.) dizia que a felicidade seria a mais desejável de todas as coisas, considerando-a o bem supremo da vida: se o homem faz alguma coisa é pensando em sua felicidade.

Durante algum tempo, o conceito de felicidade foi associado à ideia de crescimento econômico, medido pelo Produto Interno Bruto (PIB), ou, já numa linha conceitual mais ampla, a desenvolvimento econômico, através da representação do Índice de Desenvolvimento Humano (IDH). Não obstante representar um avanço conceitual, a metodologia do IDH não contempla aspectos relacionados ao meio ambiente e à sustentabilidade, atendo-se às variáveis: renda per capita, saúde e educação.

A corrente econômica liderada por Stiglitz (2009) considera que o Produto Interno Bruto (PIB) é uma ferramenta limitada para medir o progresso das sociedades, uma vez que não consegue mensurar, com eficácia, o bem-estar social de uma nação. Ao resumir toda a atividade econômica, o PIB não faz distinção entre itens que representam "custos" e itens que representam "benefícios", registrando apenas aferições de todas as transações econômicas realizadas. (LUSTOSA \& MELO, 2010).

Mas, em 1972, o $4^{\circ}$ rei do Butão - um pequeno reino situado nas encostas do Himalaia- com o apoio do Programa das Nações Unidas para o Desenvolvimento, criou o indicador sistêmico de Felicidade Interna Bruta (FIB), visando proporcionar aos governantes, diretrizes voltadas à felicidade da população.(ONU, 2002).

Enquanto os modelos tradicionais de desenvolvimento têm como objetivo primordial o mero crescimento econômico, o conceito de FIB se sustenta sobre quatro pilares: a promoção de um desenvolvimento socioeconômico sustentável e igualitário; a preservação e a promoção dos valores culturais; a conservação do meio-ambiente natural e o estabelecimento de uma boa governança. (CARVALHO, 2010).

Essa linha apresenta coerência lógica, já que, se a finalidade da administração pública é exatamente conseguir o bem comum da coletividade e que a felicidade é a razão principal da vida, os governos têm como prioridade a preocupação em implementar ações que favoreçam as condições de bemestar da sociedade. (MEIRELLES, 1995).

O FIB foi desenvolvido com base na premissa de que algumas formas de desenvolvimento, como melhorias nos aspectos sociais, econômicos e ambientais, não são mensuráveis segundo os conformes da teoria econômica 
tradicional; assim, não bastará aumentar o PIB per capita, se este não for distribuído com equidade e não levar em consideração as limitações ambientais. $\mathrm{Na}$ verdade, o PIB é parte integrante do FIB, uma vez que o crescimento econômico promove, de fato, o bem-estar e a felicidade dos mais pobres. Contudo, diversas limitações do PIB também precisam ser avaliadas, como por exemplo, a ocorrência de uma crescente desigualdade social, simultaneamente a um PIB crescente.

Apresentando nove dimensões, o FIB propõe uma abordagem diferente, alertando que, para a felicidade, faz-se necessário considerar nove dimensões, quais sejam: padrão de vida econômico, governança, educação, saúde, vitalidade comunitária, resiliencia ambiental, acesso à cultura, gerenciamento equilibrado do tempo e bem estar psicológico. Esses fatores se repetem em várias culturas; ainda que alguma delas dê maior ou menor ênfase a diferentes indicadores, eles são universalmente comuns. (ONU, 2002).

A Organização para Cooperação e Desenvolvimento Econômico (OCDE) - que concentra cerca de trinta dos países mais ricos do mundo, vem desenvolvendo um novo "Projeto Global”, através de um conjunto totalmente novo de indicadores que possibilitem uma avaliação mais realista do nível de desenvolvimento econômico dos países, na conquista de políticas sociais e econômicas que demonstrem, de fato, o potencial de incremento de satisfação com a vida, criando medidas mais consistentes de progresso. (LUSTOSA \& MELO, 2010).

A preocupação mundial de se repensar os modelos econômicos atuais, onde o cálculo da riqueza considere aspectos como a conservação do meio ambiente e a qualidade de vida, justifica a proposta deste artigo.

\section{REVISÃO DA LITERATURA}

\subsection{A EVOLUÇÃO DO CONCEITO DE ÍNDICE DE FELICIDADE}

Para Aristóteles (1991), a felicidade está relacionada a boa vida e boa ação. Mas com o tempo, a felicidade, como menciona Gianetti, apud Franco (2011; p.1), "foi se tornando matéria alheia à disciplina e pertencente ao domínio subjetivo os resultados daquelas escolhas ou da experiência interior aos indivíduos", e a economia buscava limitar-se à dimensão objetiva da disciplina.

Segundo Dasho Karma - Ura (apud Neri, 2008), a felicidade é um bem público - pois todos os seres humanos a almejam - mas é sentida no subjetivo 
individual. E tanto o poder privado quanto o público precisam criar condições que conduzam à felicidade.

Neri (2008; p. 19) coloca que:

"A principal ideia é que o conceito de felicidade subjetiva nos possibilitaria captar diretamente o bem-estar humano, ao invés de mensurar renda, ou outras coisas, que não são exatamente o que ao fim e ao cabo as pessoas querem, mas que são, ao contrario, os meios através dos quais se podem conseguir -ou não - usufruir da felicidade”. (NERI , 2008, p. 19).

Entretanto, esse distanciamento entre a solidez analítica dos fundamentos do comportamento individual e as subjetividades, se tornou um desafio para a economia. Para Franco (2011), o interesse pelos fundamentos microeconômicos da disciplina espalhou-se por toda parte, mas havia dificuldades para explicar as "irracionalidades" da coletividade formada por indivíduos racionais.

Foram nas brechas deixadas pela teoria na construção do PIB (Produto Interno Bruto), que penetraram novas influências que resultaram, por exemplo, no interesse na felicidade como tema de pesquisa.

Foi assim, que o indicador Felicidade Interna Bruta (FIB), criado no Butão, começou a colocar o conceito de felicidade em prática e atrair a atenção do resto do mundo.

Para Meneghetti Neto (2010), o conceito do Índice de felicidade se baseava na premissa de que algumas formas de desenvolvimento não são mensuráveis de forma econômica. Assim, o índice sugeria que o desenvolvimento da sociedade ocorre quando o desenvolvimento material e espiritual se dá lado a lado, se complementando e se reforçando mutuamente.

Nessa visão, o índice de felicidade estrutura-se em quatro pilares: a promoção do desenvolvimento sustentável, a preservação e promoção de valores culturais, a conservação do ambiente natural e o estabelecimento de um bom governo.

O reinado do $4^{\circ}$ rei, como menciona Santos da Silva (2011; p. 43), "serviu como um cenário de preparação para o povo e a introdução de novas políticas de descentralização", e com isso, caminhar para um bom desenvolvimento em termos de leis e políticas coerentes com o FIB. Coloca ainda, que foi em sua coroação, que o $5^{\circ}$ rei do Butão, em 2008, anunciou que a concretização da visão do FIB seria uma das quatro responsabilidades do seu reinado; as políticas públicas do Butão estariam voltadas para aplicação do FIB, tendo como objetivo final as melhorias nos aspectos sociais, econômicos e ambientais. 
Em 1999, o governo do Butão inaugurou o Centro para Estudos do Butão (CEB), com o intuito de desenvolver o FIB como um abrangente indicador socioeconômico. O CEB se preocupava em fazer do FIB um indicador transcultural e com base empírica, não baseada na filosofia tradicional ou religião budista, mas fundamentada em pesquisas cientificas sobre felicidade, elaboradas a partir de várias culturas e crenças religiosas. Embora na versão butanesa o FIB esteja relacionado a sua cultura e tradição, a versão internacional do FIB, que foi desenvolvida no Canadá e revisada para o Brasil, está desvinculada de quaisquer religiões ou culturas específicas, sendo, portanto, universal em sua abordagem.

Desde o inicio do século XXI, as Conferências Internacionais sobre o FIB começaram a ser promovidas. Primeiramente no Butão, depois em Nova Escócia, no Canadá, em 2005, em seguida, Bangcoc, na Tailândia, em 2007, novamente no Butão, em 2008, e em 2009 no Brasil. Durante esse período, o Centro de Estudos, juntamente com um grupo de especialistas internacionais e com o patrocínio do Programa das Nações Unidas para o Desenvolvimento Econômico, desenvolveu um indicador de FIB para medir esse conceito de forma qualitativa e quantitativa. O Indicador FIB é composto por nove dimensões ou domínios, considerados comuns às várias culturas, quais sejam, padrão de vida econômico, governança, educação, saúde, vitalidade comunitária, resiliencia ambiental, acesso à cultura, gerenciamento equilibrado do tempo e bem estar psicológico.

\subsection{O FIB E O DESENVOLVIMENTO SUSTENTÁVEL}

O FIB, segundo Arruda (2009), seria um instrumento e um meio para se atingir um objetivo maior: o desenvolvimento. Todavia, ele não poderia se restringir ao aspecto econômico, mas incluir o social e o humano, simultaneamente ao respeito à natureza. Para Lustosa e Melo $(2010 ;$ p. 2) "o cálculo da riqueza deve considerar outros aspectos além do desenvolvimento econômico, como a conservação do meio ambiente e a qualidade de vida das pessoas”.

Uma das nove dimensões do FIB trata a questão da Resiliência Ecológica. Arruda (2009; p.5) definiu a Resiliência Ecológica como "a capacidade de um ecossistema de recuperar seu estado inicial depois que ações humanas o alteraram"; coloca, ainda, que os processos destrutivos de ecossistemas e biomas, assim como os riscos de catástrofes ambientais de grande escala, estão ligados à lógica do capital e à formação de preços que desconsideram os custos sociais e ambientais do investimento.

Essa lógica do capital iguala desenvolvimento a crescimento econômico e obtenção máxima de lucro. No entanto, como menciona Kon e Sugahara 
(2012, p. 28), "o conceito de crescimento econômico é puramente quantitativo, quer dizer, indica somente um aumento de produção, ainda que este movimento ascendente seja durável e não aleatório”.

Para Abramovay (2012), o desenvolvimento:

"Não consiste somente na disposição de bens materiais e serviços e na possibilidade genérica de se ter acesso a eles por meio da obtenção de renda. Envolve, antes de tudo, a construção, para os indivíduos, de uma vida que vale a pena ser vivida”. (ABRAMOVAY, 2012; p.45).

Para Kon e Sugahara (2012), o desenvolvimento está relacionado ao lado qualitativo da produção, uma vez que apenas o crescimento, por si só, não é suficiente; é necessário que ele seja distribuído com justiça, de forma que o capital resultante dessa atividade seja empregado com vistas à melhoria das condições de existência da população.

Neri (2008) coloca que:

"Inúmeros países que experimentaram um aumento drástico na renda real desde a Segunda Guerra, não observaram um aumento no bem-estar auto-avaliado pela população; pelo contrário, ele diminuiu". (NERI, 2008, p. 17).

O bem-estar econômico também é uma das dimensões do FIB, entretanto, como menciona Neri (2008),

"Em um dado ponto no tempo, a renda mais alta está positivamente associada à felicidade das pessoas, contudo ao longo do ciclo de vida e ao longo do tempo, esta correlação é fraca, como no chamado Paradoxo de Easterlin.” (NERI, 2008, p. 17).

O uso do Produto Interno Bruto (PIB) como parâmetro de referência comparativa do desempenho econômico dos países vem sendo criticado, uma vez que não considera os custos dos danos ligados aos recursos ambientaisentre outros fatores não econômicos- mas que afetam o bem-estar da humanidade e a sustentabilidade do meio-ambiente.

Assim, "o FIB propõe uma abordagem diferente, baseada na noção de que, o que fazemos contra a Natureza, fazemos contra nós mesmos”. (ARRUDA, 2011; p. 5). 
E, "se há uma sintese possivel para este final de século, pode-se caracterizála como o esgotamento de um estilo de desenvolvimento que se mostrou ecologicamente predatório, socialmente perverso e politicamente injusto". (ONU, 1991; p.13).

Exemplificando, observa-se que os avanços tecnológicos surgiram para resolver problemas ou para facilitar causas especificas, sem cogitar os efeitos secundários ou colaterais: é o caso do clorofluorcarbono (CFC), descoberto em 1929, que passou a substituir a amônia como gás de refrigeração. Embora, na época, pudesse parecer útil, por ser incolor, insípido, inodoro, não tóxico, não inflamável e não reagente com outras substâncias, com o passar do tempo, verificou-se que, ao atingir a alta atmosfera, a molécula de CFC era quebrada pela radiação ultravioleta e liberava um átomo de cloro - sendo que, cada um deles, destrói até 100mil moléculas de ozônio, até ser neutralizado.

Assim, o conceito de desenvolvimento sustentável foi ganhando espaço: desde o Painel de Founex, na Suíça, em 1971, onde países em desenvolvimento e desenvolvidos discutiam os problemas ambientais, introduzindo-se o conceito de ecodesenvolvimento, até a Conferência das Nações Unidas sobre o Desenvolvimento Sustentável, Rio + 20, muitos avanços ocorreram. Questões como as mudanças climáticas e a elevação do nível do mar, desastres naturais e ambientais, gestão de resíduos, ciência e tecnologia, produção e consumo sustentável, desenvolvimento de capacidade e educação para o desenvolvimento sustentável, fazem parte do rol de preocupações internacionais contemporâneas.

\section{METODOLOGIA}

Em estudos que envolvem duas ou mais variáveis, é comum o interesse em se conhecer o relacionamento entre elas, além das estatísticas descritivas normalmente calculadas. Neste trabalho, foram elaboradas correlações lineares, tanto simples quanto múltiplas, através do cálculo do Coeficiente de Correlação Linear de Pearson:

$$
r=\frac{n \sum X Y-\sum X \sum Y}{\sqrt{\left[n \sum X^{2}-\left(\sum X\right)^{2}\right] \times\left[n \sum Y^{2}-\left(\sum^{m} Y\right)^{2}\right]}}
$$

Foi realizada, também, a análise de regressão, com a finalidade de se verificar a existência de uma relação funcional entre uma variável dependente com uma ou mais variáveis independentes. O Método dos Mínimos Quadrados (MMQ) foi aplicado nas análises de dados as regressões lineares, cuja representação algébrica genérica é dada por: $Y_{i}=\beta_{0}+\beta_{1} X_{i}+e_{i}$ 


\section{Onde:}

$Y_{i}$ : valor observado para a variável dependente $\mathrm{Y}$ no i-ésimo nível da variável independente $\mathrm{X}$. dos Y.

$\beta_{0}$ :constante de regressão representando o intercepto da reta com o eixo

$\beta_{1}$ :coeficiente de regressão, representando a variação de $\mathrm{Y}$ em função da variação de uma unidade da variável $\mathrm{X}$.

$\mathrm{X}_{\mathrm{i}}$ : i-ésimo nível da variável independente $\mathrm{X}(\mathrm{i}=, 1,2 \ldots, \mathrm{n})$.

$\mathrm{e}_{\mathrm{i}}$ : erro associado à distância entre o valor observado Yi e o correspondente ponto na curva, do modelo proposto, para o mesmo nível i de $\mathrm{X}$.

De modo que $\beta_{0}$ e $\beta_{1}$ é dado pelas estimativas:

$$
b=\frac{\sum X Y-\frac{\sum X \sum Y}{n}}{\sum x^{2}-\frac{\left(\sum X\right)^{2}}{n}} \quad a=\frac{\sum Y}{n}-b \frac{\sum X}{n}
$$

Foi utilizada, também, a Análise Fatorial, que é formada por um conjunto de técnicas estatísticas, e possui como objetivo reduzir o número de variáveis iniciais com a menor perda possível de informação. Portanto, na análise fatorial, essas muitas variáveis dependentes sugerem que um número menor de dimensões (fatores) pode ser suficiente para explicar a variação que ocorre entre elas. Lira (2004).

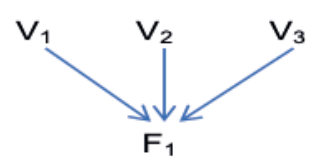

Figura 1: Análise fatorial

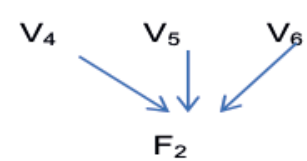

Fonte: Elaboracão própria

A representação matemática da análise fatorial é dada por:

Onde:

$$
X_{i}=\sum a_{i j} F_{j}+e_{i}
$$

$\mathrm{X}_{\mathrm{i}}$ : variável padronizada i a ser analisada i e os fatores $\mathrm{j}$

$\mathrm{F}_{\mathrm{j}}$ : fatores $\mathrm{j}$ comuns não correlacionados entre si

$e_{i}:$ erro 
O quadrado da carga fatorial representa o quanto do percentual da variação de uma variável é explicada por cada fator.

Os fatores poderiam ser estimados por uma combinação linear das variáveis originais, como demonstrado abaixo:

$$
F_{j}=\sum \omega_{j i} X_{i}
$$

Onde:

$\mathrm{F}_{\mathrm{i}}$ : fatores comuns não correlacionados

$\mathrm{X}_{\mathrm{i}}$ :variável original padronizada $\mathrm{i}$

$\Omega_{\mathrm{ji}}$ : coeficientes dos escores fatoriais

O escore fatorial é um número resultante da multiplicação dos coeficientes wji pelo valor das variáveis originais. Quando existe mais de um fator, o escore fatorial representa as coordenadas da variável em relação aos eixos, que são os fatores.

Dentre as medidas para avaliação da adequação da AF para o tratamento dos dados, estão as medidas KMO - Kaiser-Meyer-Olkin, e Bartlett's teste ofSphericity (Teste de esfericidade de Bartlett).

KMO - kaiser-Meyer-Olkin mede o grau de correlação parcial entre as variáveis, índice usado para avaliar a adequadicidade da análise fatorial. Valores altos (entre 0,5 e 1,0) indicam que a análise fatorial é apropriada. Valores abaixo de 0,5 indicam que a análise fatorial pode ser inadequada.

Bartlett's teste of sphericity é uma estatística de teste usada para examinar a hipótese de que as variáveis não sejam correlacionadas na população; indica se a matriz de correlação é uma matriz identidade (correlação zero entre as variáveis). Valores superiores a 0,05 não indicam adequação suficiente.

Segundo Vicini (2005; p.38-39), a Communality (comunalidade) é a medida de quanto da variância, de uma variável, é explicada pelos fatores derivados pela análise fatorial. Avalia a contribuição da variável ao modelo construído pela AF, ou seja, o quanto cada variável participa na formação da outra. Nas communality, os valores mais altos são os mais importantes para análise.

O método para extração de fatores utilizado neste trabalho foi o método da Análise dos Componentes Principais (ACP).

Segundo Vicini (2005), a ACP é uma técnica matemática da análise multivariada, que possibilita investigações com um grande número de dados disponíveis. Possibilita, também, a identificação das medidas responsáveis pelas maiores variações entre os resultados, sem perdas significativas de informações. 
Vicini (2005) coloca que a meta da análise de componentes principais é abordar aspectos como a geração, a seleção e a interpretação das componentes investigados.

Pretende-se, ainda, determinar as variáveis de maior influência na formação de cada componente. A Análise de Componentes Principais transforma o conjunto de variáveis originais em outro conjunto com a menor perda possível de informações.

\section{OBTENC̣ÃO E ANÁLISE DOS DADOS}

Conforme a literatura referida, o FIB é composto por nove dimensões, quais sejam: padrão de vida econômico, governança, educação, saúde, vitalidade comunitária, resiliência ambiental, acesso à cultura, gerenciamento equilibrado do tempo e bem estar psicológico.

A princípio, procurou-se verificar se existiam correlações entre algumas variáveis que pudessem explicar uma ou outra dimensão do FIB, como mostrado no Quadro 1.

Procurou-se coletar dados em forma de série histórica, entretanto, para alguns, não foi encontrada uma grande base de dados significativa. Foram procurados, também, indicadores que tivessem uma abrangência representativa em todo o Brasil, obtendo-se a síntese de indicadores usados na análise, quais sejam:

- População não estudante

- Taxa de Alfabetização

- Renda Desigualdade - coeficiente de Gini

- Renda per Capita média

- PIB

- Participação do $1 \%$ mais rico

- Renda Média dos Extremamente Pobres

- Taxa de Extrema Pobreza

- Taxa de Mortalidade Infantil

- Taxa de Suicídio

- Expectativa de Vida

- Emissões de $\mathrm{CO}^{2}$ de escapamento por veículos do ciclo Otto (milt/ano)

- Desflorestamento

- Evolução da Frota estimada de veículos do ciclo Otto

- Balanço entre absolvição e Emissão de $\mathrm{CO}^{2}$ nos estados do Norte do Brasil

- Taxa de Crescimento Populacional 
- Taxa Bruta de Natalidade

- Taxa de Fecundidade Total

- Taxa de Homicídio

Quadro 1: Indicadores e Dimensões (variáveis para correlação)

\begin{tabular}{|c|c|c|c|c|}
\hline \multicolumn{5}{|c|}{ DIMENSÕES } \\
\hline G1 & G2 & G3 & G4 & G5 \\
\hline EDUCAÇÃOO & $\begin{array}{l}\text { PADRÃO DE VIDA } \\
\text { ECONÔMICO }\end{array}$ & SAÚDE & $\begin{array}{l}\text { RESILIÊNCIA } \\
\text { AMBIENTAL }\end{array}$ & $\begin{array}{l}\text { VITALIDADE } \\
\text { COMUNITÁRIA }\end{array}$ \\
\hline $\begin{array}{l}\text { POPULAC,̃̃O NÃO } \\
\text { ESTUDANTE }\end{array}$ & $\begin{array}{l}\text { RENDA DESIGUALDADE } \\
\text { - COEFICIENTE DE GINI }\end{array}$ & $\begin{array}{l}\text { TAXA DE MORTALIDADE } \\
\text { INFANTIL }\end{array}$ & $\begin{array}{l}\text { EMISSÕES DE CO2 DE } \\
\text { ESCAPAMENTO POR } \\
\text { VÉ́CULOS DO CICLO } \\
\text { OTTO (MIL T/ANO) }\end{array}$ & $\begin{array}{c}\text { TAXA DE CRESCIMENTO } \\
\text { POPULACIONAL }\end{array}$ \\
\hline \multirow[t]{5}{*}{ TAXA DE ALFABETIZAC̦ÃO } & RENDA PER CAPITA MÉDIA & $\begin{array}{l}\text { TAXA DE SUICÍDIO } \\
\text { (PODENDO REPRESENTAR } \\
\text { BEM-ESTAR PSICOLÓGICO } \\
\text { COMO VITALLDADE } \\
\text { (OMUNITÍRIA) }\end{array}$ & DESFLORESTAMENTO & $\begin{array}{l}\text { EXPECTATIVA DE } \\
\text { VIDA AO NASCER }\end{array}$ \\
\hline & PIB & $\begin{array}{l}\text { EXPECTATIVA DE } \\
\text { VIDA AO NASCER }\end{array}$ & $\begin{array}{l}\text { EVOLUÇÃO DA FROTA } \\
\text { ESTIMADA DE VÉCCLLOS } \\
\text { DO CICLO OTTO }\end{array}$ & TAXA DE NATALLDADE \\
\hline & $\begin{array}{c}\text { PARTICIPAC,ÃO DOS } \\
1 \% \text { MAIS RICOS }\end{array}$ & & $\begin{array}{l}\text { BALANC̦O TGCO² (SOMA } \\
\text { DOS ESTADOS)BALANÇO } \\
\text { ENTRE EMISSÕES E } \\
\text { ABSOLVIC̦ÃO DE CO2 POR } \\
\text { DESMATAMENTO FLORESTA } \\
\text { PRIMÁRIA E SECUNDÁRIA }\end{array}$ & $\begin{array}{c}\text { TAXA DE FECUNDIDADE } \\
\text { TOTAL }\end{array}$ \\
\hline & $\begin{array}{c}\text { RENDA MÉDIA DOS } \\
\text { EXTREMAMENTE POBRES }\end{array}$ & & & TAXA DE HOMICÍDIO \\
\hline & TAXA DE EXTREMA POBREZA & & & \\
\hline
\end{tabular}

Fonte: Elaboração própria

\section{RESULTADOS}

Como mencionado, foram coletados indicadores que supostamente possuíam fortes correlações, podendo ser indicadores interindependentes ou interdependentes. Foram agrupados em uma das nove dimensões do FIB, no intuito de identificar se variáveis que, aparentemente, não possuíam nenhuma 
correlação, possuíam fortes relações e vice-versa. Para tanto, foram utilizados recursos do SPSS e do Excel.

A análise sugere que existe uma forte correlação negativa entre as variáveis: População não Estudante e Taxa de Alfabetização - o que já era esperado, uma vez que, ao se aumentar a taxa de alfabetização, espera-se que a população de estudante aumente, e, portanto, que a população dos não estudantes diminua.

O Indicador Renda per Capita Média dos Extremamente Pobres pouco se relaciona com as demais variáveis, o que faz supor que este dado não entrará nos próximos estudos, ou não é significante na análise.

Segundo os resultados obtidos, o PIB teria uma forte relação negativa com todas as variáveis estudadas, exceto com a Renda per Capita Média. O que sugere que, quanto maior for o PIB, menores serão as desigualdades, a taxa de extrema pobreza e a participação do $1 \%$ mais rico no PIB.

Obteve-se que, quanto maior a taxa de mortalidade infantil, menor será a esperança (expectativa) de vida e menor será a taxa de suicídio. E quanto menor for a taxa de mortalidade infantil, maior será a esperança de vida e a taxa de suicídios.

Segundo o IBGE, a taxa de mortalidade infantil está positivamente associada ao desenvolvimento socioeconômico e à extensão e qualidade da infraestrutura ambiental, bem como ao acesso aos recursos disponíveis para atenção à saúde materna e da população em geral. Assim sendo, seria de se esperar que, quanto menor a taxa de Mortalidade Infantil, maior seria a Esperança de Vida; mas não se esperava que quanto menor a taxa de Mortalidade Infantil, maior seria a Taxa de Suicídio.

Em termos de resiliência ambiental, a análise indica que o desflorestamento apenas possui uma correlação significativa com o Balanço entre Emissões e Absolvição de $\mathrm{CO}^{2}$ nos Estados do Norte do Brasil. E que a Evolução da Frota de veículos do ciclo Otto melhor se relaciona com as Emissões de $\mathrm{CO}^{2}$ de escapamento por veículos do Ciclo Otto; desse modo, sugere dois estudos distintos.

Os resultados indicam que todos os indicadores estão fortemente relacionados, positiva ou negativamente. A Expectativa de Vida se relaciona forte e inversamente com todos os indicadores estudados no Grupo, exceto com a Taxa de Homicídio, o que supõe que quanto maior a expectativa de vida menor serão as taxas de fecundidade, natalidade e crescimento populacional.

Os resultados preliminares obtidos nos cálculos de correlação, por meio do coeficiente de Pearson, identificaram fortes relações entre as variáveis, direcionando o trabalho para a análise fatorial de dados grupais, com o 
intuito de extrair de cada grupo (dimensão) um ou dois indicadores que possam representar o grupo, como sugere a análise fatorial.

Os resultados obtidos nos cálculos de análise fatorial foram obtidos com o apoio do software SPSS. O resultado da análise fatorial indica que há um fator que representa as duas variáveis estudadas, explicando $97,67 \%$ da variância total. Como ambos indicadores possuem o mesmo grau de comunalidade $(0,977)$, neste caso, arbitrariamente, se fará o uso do indicador Taxa de Alfabetização para representar o grupo em análises futuras.

A análise fatorial feita no grupo G2 - Padrão de Vida Econômico- mostrou que há dois fatores que podem explicar $82,77 \%$ da variância total. O Fator I explicaria as variáveis: Renda desigualdade - coeficiente de Gini e Participação do $1 \%$ mais rico. E o Fator II explicaria as variáveis: Renda per capita média dos extremamente pobres, Renda per capita média, Taxa de extrema pobreza e PIB.

Sendo assim, serão usados os seguintes indicadores para representar o grupo em análises futuras: Renda desigualdade coeficiente de Gini (comunalidade de 0,942), correspondente do fator 1, e o PIB (comunalidade de 0,898), correspondente do fator 2.

Verificou-se que há um fator que pode representar o grupo, explicando 96,68\% da variância total; desse modo, será usada a Taxa de Mortalidade Infantil, cuja comunalidade é a maior do grupo $(0,983)$ para representar o grupo em análises futuras.

Em relação à resiliência ambiental, os resultados obtidos na análise fatorial indicam que há dois fatores que podem representar o grupo, explicando 87,71\% da variância total. Sendo os componentes do Fator 1: Evolução da Frota estimada de veículos do ciclo Otto - Gasolina e Emissões de $\mathrm{CO}^{2}$ de escapamento por veículos do ciclo Otto e o Fator 2 representado por: Balanço $\mathrm{TgCO}^{2}$, soma dos estados e Desflorestamento total Km/ano. Com isso, os indicadores que poderão ser usados para representar o grupo são Emissões de $\mathrm{CO}^{2}$ de escapamento por veículos do ciclo Otto e Desflorestamento total Km/ano.

Os resultados apontam que há um fator em comum entre as variáveis, que explica $89,85 \%$ da variância total.

Assim, o indicador com maior comunalidade será o indicador que representará o grupo em análise futuras; portanto, este indicador será a Expectativa de Vida, cuja comunalidade é de 0,988.

Um novo estudo será feito, considerando as variáveis que representam cada grupo com o intuito de relacionar os representantes das cinco dimensões do FIB e desse modo verificar se há correlações entre as variáveis, assim como estabelecer um modelo matemático que possa representar o FIB. 
Este novo estudo foi feito levando em consideração as seguintes variáveis, obtidas por meio das análises fatoriais:

Quadro 2:Indicadores e Dimensões ( análises fatoriais)

\begin{tabular}{|c|c|c|c|c|}
\hline \multicolumn{5}{|c|}{ DIMENSÕES } \\
\hline EDUCAC̣̃̃O & $\begin{array}{l}\text { PADRÃO DE VIDA } \\
\text { ECONÔMICO }\end{array}$ & SAÚDE & $\begin{array}{l}\text { RESILIÊNCIA } \\
\text { AMBIENTAL }\end{array}$ & $\begin{array}{l}\text { VITALIDADE } \\
\text { COMUNITÁRIA }\end{array}$ \\
\hline \multirow[t]{2}{*}{ TAXA DE ALFABETIZAÇÃO } & $\begin{array}{l}\text { RENDA DESIGUALDADE } \\
\text { - COEFIIIENTE DE GINI }\end{array}$ & $\begin{array}{l}\text { TAXA DE MORTALLDADE } \\
\text { INFANTIL }\end{array}$ & DESFLORESTAMENTO & EXPECTATIVA DE VIDA \\
\hline & PIB & & $\begin{array}{l}\text { EMISSÕES DE CO2 DE } \\
\text { ESCAPAMENTO POR } \\
\text { VÉĆCULOS DO CICLO } \\
\text { OTTO (MIL T/ANO) }\end{array}$ & \\
\hline
\end{tabular}

Fonte: Elaboração própria

O resultado final da analise fatorial apontou para um representante dos indicadores que compuseram as 5 dimensões estudadas.

Entretanto, para um melhor ajuste e avaliação foi acrescentado ao representante do Grupo 5 a Taxa de Fecundidade; as variáveis Desigualdade coeficiente de Gini e Desflorestamento tiveram que ser desprezadas, uma vez que não possuíam fortes correlações com todas as variáveis. Os resultados foram os seguintes:

Quadro 3: Variância Total Explicada

\begin{tabular}{ccccccc}
\hline \multirow{2}{*}{ COMPONENTES S INITIAL EIGENVALUES } & \multicolumn{3}{c}{ INITIAL EIGENVALUES } \\
\cline { 2 - 7 } & TOTAL & \% OF VARIANCE & CUMULATIVE \% & TOTAL & \% OF VARIANCE & CUMULATIVE \% \\
\hline 1 & 5,462 & 91,033 & 91,033 & 0,462 & 91,033 & 91,033 \\
\hline 2 & 0,457 & 7,619 & 98,652 & & & \\
\hline 3 & 0,072 & 1,202 & 99,853 & & \\
\hline 4 & 0,005 & 0,082 & 99,936 & & \\
\hline 5 & 0,004 & 0,061 & 99,997 & & & \\
\hline 6 & 0,000 & 0,003 &, 000 & & & \\
\hline
\end{tabular}

Fonte: Elaboracãõo própria

Como representado acima, a análise identificou que há um fator em comum entre as variáveis e que este explicaria 91,03\% da variância total. Dessa 
forma, escolhe-se o indicador com o maior valor de comunalidade - no caso, a Expectativa de Vida. Portanto, o indicador Expectativa de vida representará todos os Grupos ou Dimensões e analogamente o FIB.

Diante desses resultados, procurou-se relacionar a Expectativa de Vida com os demais indicadores, numa regressão linear, de modo que a Expectativa de Vida seria a Variável Dependente Y e os demais indicadores seriam as Variáveis Independentes $\mathrm{Xi}$, ,estabelecendo-se, assim, um modelo matemático que pudesse explicar o FIB por meio das variações ocorridas com determinados indicadores; e ainda, verificar quais indicadores seriam relevantes para estabelecer o modelo de regressão e a forma como estes se relacionam com a Expectativa de vida. Os resultados estão descritos no Quadro 4.

\section{Quadro 4 :Indicadores relevantes}

\begin{tabular}{|c|c|c|c|c|}
\hline & COEFICIENTES & ERRO PADRÃO & STAT T & VALOR-P \\
\hline INTERSEÇ̃̃̃O & 81,54964 & 0,152666 & 534,168946 & $1,24 E-25$ \\
\hline $\begin{array}{l}\text { EMISSÕES DE CO2DE } \\
\text { ESCAPAMENTO POR } \\
\text { VÉ́CULOS DO CICLO OTTO } \\
\text { (MIL T/ANO) - GASOLINA A }\end{array}$ & $-1,2 \mathrm{E}-05$ & $2,76 \mathrm{E}-06$ & 4,48028965 & 0,000931 \\
\hline $\begin{array}{l}\text { TAXA DE MORT INF. / } \\
\text { 1.000 RECÉM-NASCIDOS } \\
\text { ANUAL (1990-2009) }\end{array}$ & $-0,22393$ & 0,005181 & $-43,2176825$ & $1,24 \mathrm{E}-13$ \\
\hline TAXA DE FECUNDIDADE & $-1,65462$ & 0,114472 & 14,4544072 & $1,68 \mathrm{E}-08$ \\
\hline $\begin{array}{l}\text { DESFLORESTAMENTO } \\
\text { TOTAL (KM²/ANO) }\end{array}$ & $-0,09447$ & 0,048898 & 1,93191284 & 0,079528 \\
\hline
\end{tabular}

Fonte: Elaboração própria

Como sugere a análise de regressão, a Expectativa de Vida, que representa o FIB neste estudo, se relaciona negativamente com os indicadores Taxa de Fecundidade, Taxa de Mortalidade Infantil, Emissões de $\mathrm{CO}^{2}$ de escapamento por veículos do ciclo Otto e Desflorestamento, e esses indicadores seriam os coeficientes, juntamente com a constante, do modelo linear do FIB, qual seja:

$\mathrm{E}=-1,2 \times 10^{-5} \mathrm{X}_{\mathrm{I}}-0,224 \mathrm{X}_{\mathrm{II}}-1,65 \mathrm{X}_{\mathrm{III}}-0,09 \mathrm{X}_{\mathrm{IV}}+81,55$

Onde,

$\mathrm{E}=$ Expectativa de Vida, representando o FIB; 
$\mathrm{X}_{\mathrm{I}}=$ Emissões de $\mathrm{CO}^{2}$ de escapamento por veículos do ciclo Otto;

$\mathrm{X}_{\mathrm{II}}=$ Taxa de Mortalidade Infantil por 1.000 recém-nascidos;

$\mathrm{X}_{\mathrm{III}}=$ Taxa de Fecundidade;

$\mathrm{X}_{\mathrm{IV}}=$ Desflorestamento Km/ano.

O coeficiente de Explicação (R quadrado) reduziu os erros em 99,75\% e o coeficiente de Pearson (coeficiente de correlação) foi de 99,99\%. Também foram analisados os erros padronizados, e apenas 1 ou $6,25 \%$ do total erros padronizados foram superiores a 2 - considerando uma distribuição normal ao nível de confiança de $95 \%$ - assim como os erros percentuais foram menores que $0,1 \%$.

\section{CONCLUSÃO}

Como demonstram os dados, o PIB possui uma relação direta com a redução da taxa de extrema pobreza.

A taxa de mortalidade infantil, segundo o IBGE, está positivamente associada ao desenvolvimento socioeconômico e à extensão e qualidade da infraestrutura ambiental, bem como ao acesso aos recursos disponíveis para atenção à saúde materna e da população em geral. Portanto, o aumento do PIB também representaria uma redução na taxa de mortalidade infantil e, conforme demonstrado nas análises, aumentou também a expectativa de vida e, consequentemente, melhorias na qualidade de vida.

Porém, os resultados das correlações, feitas inicialmente em cada grupo, mostrou que o Grupo 2, que representa a dimensão Saúde, apresentou um resultado não esperado. A redução da mortalidade infantil e o aumento da expectativa de vida - condições que indicam melhorias na qualidade de vida, reafirmadas pelos resultados obtidos nos estudos preliminares realizados no Grupo 5 (onde à medida que a Expectativa de vida aumentasse, as taxas de fecundidade, natalidade e crescimento populacional seriam reduzidas) indicaram um aumento na taxa de suicídio.

Fica claro que PIB, Renda per Capita e outros indicadores econômicos não visam medir o bem-estar das populações. Esses indicadores de riqueza são tão somente facilitadores para acesso a bens e serviços (ex.: boa educação, planos de saúde, bens materiais que trazem conforto, entre outros), importantes para a obtenção de bem-estar. Diante da primeira restrição encontrada na análise de correlação do Grupo 2, já se pode questionar a eficiência do PIB como medida de bem-estar econômico e social. 
Ao analisar indicadores que representavam as dimensões escolhidas para este estudo, verificou-se que a expectativa de vida seria o indicador que melhor representaria o conjunto de indicadores; ou seja, mais uma vez o PIB não foi considerado o melhor indicador.

Mas, ao analisar a Expectativa de vida conjugada aos demais indicadores, com o intuito de estabelecer um modelo matemático, observou-se que as variáveis de Padrão de Vida Econômico e Educação não entraram no modelo: participaram dele, dois fatores ambientais, um de vitalidade comunitária e um de saúde, apontando para um novo olhar sobre a questão do bem-estar.

Reforçando a posição de Mankiw (2010), que afirma que o PIB não mede diretamente as coisas que fazem a vida valer a pena, mas mede nossa capacidade de obter os insumos para uma vida que valha a pena, observa-se que o PIB não é uma medida perfeita de bem-estar, já que ele não inclui aspectos que contribuem para uma boa qualidade de vida.

O modelo matemático gerado pela regressão indica que tais fatores se centrariam na redução da Taxa de Mortalidade Infantil, da Taxa de fecundidade, do Desflorestamento e das Emissões de $\mathrm{CO}^{2}$ de escapamento de veículos do ciclo Otto.

Não obstante, a redução da Taxa de Mortalidade Infantil e da Taxa de Fecundidade poder ser explicada pelo aumento do PIB, em contrapartida, o aumento do PIB representa o aumento das Emissões de $\mathrm{CO}^{2}$ de escapamento de veículos do ciclo Otto.

Desse modo, pode-se dizer que a metodologia apresentada pelo FIB surge com o intuito de complementar os indicadores existentes, acrescentando à análise de bem-estar social variáveis não consideradas pela economia neoclássica: torna-se necessário acrescentar a variável ambiental, que, como indicado nos resultados obtidos, demonstra grande representatividade nesse contexto mais geral de qualidade de vida. 


\section{Abstract}

There is a challenge in the twenty-first century for quality measurement indicators of life of countries, not just based on indicators such as life expectancy, education and gross domestic product, but to consider, too, the degree of satisfaction of the population in relation to subjective public goods. This article aims to analyze the new metric development, which is based on the achievement of social welfare with environmental sustainability, through the window of Gross National Happiness (GNH). Based on this assumption, the objective of the analysis focuses on assessing the extent to which the FIB constitutes a measure that complements the Gross Domestic Product (GDP) in order to guide decision-makers of public policies towards a better quality of life. Therefore, the conceptual placements of some authors about happiness and sustainability were reviewed and used statistical methods of analysis, as correlational and regression analysis, considering the nine dimensions that make up the FIB, namely: standard economic life, governance, education, health, community vitality, environmental resilience, access to culture, balanced time management and psychological well-being. It was concluded that the Gross Domestic Product (GDP) is an incomplete indicator, and that the FIB would be a complementary alternative, indicating a better way to happiness.

Keywords: Internal Gross, Gross Domestic Product, Sustainable Happiness. 


\section{REFERÊNCIAS}

ABRAMOVAY, R. Muito além da economia verde. São Paulo: Ed. Abril, 2012.

ARISTÓTELES. Ética a Nicômaco. $4^{a}$ Ediç̃̃o. São Paulo: Nova Cultural, 1991.

ARRUDA, M. As nove dimensões do FIB. São Paulo: Instituto Visão Futuro Parque Ecológico. 2009.

CARVALHO, M. B. de. A Felicidade na agenda da administração e suas relações com conceitos organizacionais. Tese de Mestrado. Minas Gerais: Faculdade FUMEC, 2010.

FRANCO, G. H. B. Índices de felicidade e desenvolvimento econômico. Portugal: Fundaç̃õo Calouste Gulberklain. 2011.

KON, A; SUGAHARA, C. Sustentabilidade e empregos verdes no Brasil. Curitiba: Ed. Appris, 2012.

LIRA, S. A. Análise de correlação: Abordagem teórica e de construção dos coeficientes com aplicações. Paraná: Universidade Federal do Paraná, 2004.

LUSTOSA, A. E; MELO, L. F. de. Felicidade Interna Bruta (FIB) - Índice de desenvolvimento sustentável. Brasilia: Conjuntura econômica goiana, 2010.

MANKIW, N. G. Introdução a Economia. Ed.: Cengage Learning. $3^{0}$.Ediç̦ão, 2005.

MEIRELLES, H.L. Direito administrativo brasileiro. São Paulo: Malheiros, 1995.

MENEGHETII NETO; A. 0 índice de felicidade: evolucção e crítica. In: Projeto Fé e Cultura. PUCRS, março de 2010. NERI, M. C., Jovens, educação, trabalho e o índice de felicidade futura. Centro de Estudos Sociais, Rio de Janeiro: Fundação Getúlio Vargas, 2008.

ONU. PublicaçãoJohannesbourgSummit. World Summit on Sustainable Development. United NationsDepartment of Publiclnformation, 2002.

ONU. 0 Desafio do desenvolvimento sustentável. Relatório do Brasil a Conferência das Naç̦es Unidas sobre 0 Meio Ambiente e Desenvolvimento. 1991.

SANTOS DA SILVA, Fabiana. Felicidade Interna Bruta em Serra Grande, Bahia. Bahia: Instituto de Pesquisas Ecológicas; 2011.

STIGLITZ, J. Problemas do PIB como um Barômetro Econômetro. New York: New York Times, 2009.

VICINI, L. Análise Multivariada da Teoria à Prática. Rio Grande do Sul: Universidade Federal de Santa Maria, 2005. 